\title{
Generation and Characterization of a Nanobody Against SARS-CoV
}

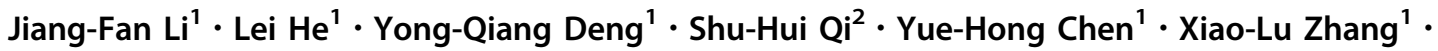 \\ Shi-Xiong $\mathrm{Hu}^{2} \cdot$ Rui-Wen Fan $^{2} \cdot$ Guang-Yu Zhao ${ }^{1}$ (1) Cheng-Feng Qin ${ }^{1,3}$ (D)
}

Received: 28 March 2021 / Accepted: 6 May 2021 / Published online: 17 August 2021

(C) The Author(s) 2021

\begin{abstract}
The sudden emergence of severe acute respiratory syndrome coronavirus (SARS-CoV) has caused global panic in 2003, and the risk of SARS-CoV outbreak still exists. However, no specific antiviral drug or vaccine is available; thus, the development of therapeutic antibodies against SARS-CoV is needed. In this study, a nanobody phage-displayed library was constructed from peripheral blood mononuclear cells of alpacas immunized with the recombinant receptor-binding domain (RBD) of SARS-CoV. Four positive clones were selected after four rounds of bio-panning and subjected to recombinant expression in E. coli. Further biological identification demonstrated that one of the nanobodies, S14, showed high affinity to SARS-CoV RBD and potent neutralization activity at the picomole level against SARS-CoV pseudovirus. A competitive inhibition assay showed that S14 blocked the binding of SARS-CoV RBD to either soluble or cell-expressed angiotensinconverting enzyme 2 (ACE2). In summary, we developed a novel nanobody targeting SARS-CoV RBD, which might be useful for the development of therapeutics against SARS.
\end{abstract}

Keywords Severe acute respiratory syndrome coronavirus (SARS-CoV) - Receptor-binding domain (RBD) . Nanobody $\cdot$ Neutralizing antibody

\section{Introduction}

Coronaviruses are a large family of viruses within the family Coronaviridae, and the order Nidovirales, which are mainly divided into four groups. They may cause diseases of different severities in various animals (Zaki et al. 2012). The first human coronavirus that caused a global outbreak was severe acute respiratory syndrome coronavirus (SARS$\mathrm{CoV}$ ), which was first found in Guangdong Province, China in November 2002 (Ksiazek et al. 2003; Peiris et al.

Cheng-Feng Qin

qincf@bmi.ac.cn

$\triangle$ Guang-Yu Zhao

guangyu0525@163.com

1 State Key Laboratory of Pathogen and Biosecurity, Beijing Institute of Microbiology and Epidemiology, Academy of Military Medical Sciences (AMMS), Beijing 100071, China

2 College of Veterinary Medicine, Shanxi Agriculture University, Jinzhong 030801, China

3 Research Unit of Discovery and Tracing of Natural Focus Diseases, Chinese Academy of Medical Sciences, Beijing 100071, China
2003). Several weeks later, it had spread to 25 countries causing at least 8000 infections. By July 3, 2003, 8439 cases had been reported, resulting in 812 deaths (Kuiken et al. 2003). On July 5, 2003, the World Health Organization declared the world free of ongoing SARS transmission. However, there were four sporadic SARS cases reintroduced from animals in Guangdong China in late 2003 and early 2004, of which the virus isolates were different from the previous outbreak (Liang et al. 2004). In total, three instances of laboratory-acquired infections occurred in Singapore, Taiwan and Beijing (Anderson and Tong 2010). Thus, the possibility of reintroduction of SARS-like-CoVs from animals and the leakage of SARS$\mathrm{CoV}$ from the laboratory are still concerned (Du et al. 2009). Although no case has been reported for years, there is a possibility of a new outbreak of SARS. Unfortunately, there are no effective antivirals or licensed vaccines to treat or prevent SARS.

As they both belong to lineage B of the Betacoronavirus genus, SARS-CoV, and the ongoing disastrous SARSCoV-2 share $79 \%$ genome sequence identity (Lu et al. 2020), the latter of which has led to over 194 million infections and 4 million deaths (https://covid19.who.int). 
The genome of SARS-CoV encodes four major structural proteins: spike (S), membrane (M), envelope (E), and nucleocapsid (N) proteins (Tsunetsugu-Yokota et al. 2006). The $\mathrm{S}$ protein is a type I membrane glycoprotein that consists of two distinct functional domains. The S1 domain near the amino terminus mediates the binding between SARS-CoV and its receptor, angiotensin-converting enzyme 2 (ACE2). The S2 domain near the carboxy terminus mediates membrane fusion. Neutralizing antibodies are mainly induced by the $\mathrm{S}$ protein (Gallagher and Buchmeier 2001). Furthermore, the receptor-binding domain (RBD), which is located in the middle of $\mathrm{S} 1$ where $S$ interacts with ACE2, contains neutralizing epitopes that induce potent neutralizing antibodies in animal models ( $\mathrm{He}$ et al. 2004).

Neutralizing antibodies play an important role in protecting against infectious diseases. Previous studies have reported that SARS patients receiving SARS convalescent plasma therapy showed clinical improvement (Pearson et al. 2003; Cheng et al. 2005). Moreover, passive transfer of serum from mice immunized with SARS-CoV to naïve mice resulted in reduced lung viral load following virus challenge (Subbarao et al. 2004). A monoclonal antibodybased on the B cells of a convalescent patient significantly reduced the viral load in the upper respiratory tract of mice that received antibody treatment before challenge (Traggiai et al. 2004). Another monoclonal antibody identified from immunized human immunoglobulin transgenic mice alleviated viral load and associated pathological findings in a golden Syrian hamster model after exposure (Roberts et al. 2006). These results revealed that neutralizing antibodies are potent prophylactic and therapeutic agents.

Nanobodies from heavy chain antibodies naturally occur in camels (Hamers-Casterman et al. 1993), representing an attractive weapon against infectious diseases. Its size, $2.5 \mathrm{~nm}$ in diameter and nearly $4 \mathrm{~nm}$ high, with a molecular weight of about $15 \mathrm{kDa}$, makes it the smallest antigenbinding antibody fragment to date (Wang et al. 2019). It is quite stable at extreme temperatures and $\mathrm{pH}$ values (Ebrahimizadeh et al. 2013). It can also recognize unique epitopes that are not accessible to conventional antibodies (Lauwereys et al. 1998). These characteristics give nanobodies their great therapeutic value.

In this study, we established a phage-displayed nanobody library from alpacas immunized with recombinant SARS-CoV RBD protein. Further screening and characterization identified a nanobody, S14, with potent neutralization against SARS-CoV. The platform described here provides a useful tool to rationally develop novel nanobodies against emerging viruses with global impact.

\section{Materials and Methods}

\section{Cells and Proteins}

All cells used in this study were cultured at $37{ }^{\circ} \mathrm{C}$ with $5 \%$ $\mathrm{CO}_{2}$. Dulbecco's minimum essential medium (DMEM) complete medium containing $10 \%$ fetal bovine serum and $1 \%$ penicillin/streptomycin was used for cell growth and replaced with DMEM without any additives after transfection. 293T cells were used for recombinant RBD protein expression and SARS-CoV pseudovirus production. HeLa cells stably expressing human ACE2 (HeLa-ACE2), kindly provided by Prof. Zheng-Li Shi (Wuhan Institute of Virology, Chinese Academy of Sciences), were used for flow cytometry.

Recombinant SARS-CoV RBD protein fused with rabbit IgG-Fc tag (RBD-rFc; SinoBiological) was used for alpacas immunization, bio-panning, identification, and flow cytometry. Recombinant rabbit IgG-Fc protein $(\mathrm{rFc}$; SinoBiological) was used to remove $\mathrm{rFc}$-specific phage antibodies during bio-panning.

\section{Alpacas Immunization}

A one-year-old female alpacas was subcutaneously immunized with $200 \mu \mathrm{g}$ recombinant SARS-CoV RBD-rFc protein plus Freund's complete adjuvant, and boosted three times with the same protein plus Freund's incomplete adjuvant every two weeks. Before immunization, blood samples of alpacas were collected for SARS-CoV-RBDspecific antibody detection. The housing and care of alpacas and the study protocols were approved by the Animal Experimentation Ethics Committee of Shanxi Agricultural University (2018).

\section{Construction of SARS-CoV-RBD-Specific Phage- Displayed Nanobody Library and Bio-Panning}

A phage-displayed library was constructed as previously described (Zhao et al. 2018). Briefly, ten days after the final immunization, anticoagulant blood was collected from the jugular vein (Fig. 1). Peripheral blood mononuclear cells (PBMCs) were isolated by Ficoll-Paque gradient centrifugation and total RNA was extracted using TRIzol reagent. First-strand cDNA synthesis was performed by reverse transcription PCR using total RNA as a template. The gene of the variable region of the heavy chain of heavy chain antibody (VHH) was amplified by nested PCR. The first primer pair (forward: 5'-GGTGGTCCTGGCTGC-3'; reverse: 
Fig. 1 Generation and identification of SARS-CoVRBD-specific nanobody. A Schematic illustration of the construction of SARS-CoV nanobody library and generation of SARS-CoV-RBD-specific nanobody. $R B D-r F c$ SARSCoV RBD with rabbit IgG-Fc tag (Sino biological), FCA Freund's complete adjuvant, FICA Freund's incomplete adjuvant, $V H H$ variable region of heavy chain antibody. B SDS-PAGE analysis of purified SARS-CoV nanobodies. $M$ Marker. The molecular weight is indicated on the left. C Evaluation of the binding activity between SARSCoV RBD and nanobodies. Results are presented as the mean values of optical density at the absorbance of $450 \mathrm{~nm} \pm$ standard deviation $(\mathrm{n}=2)$.
A
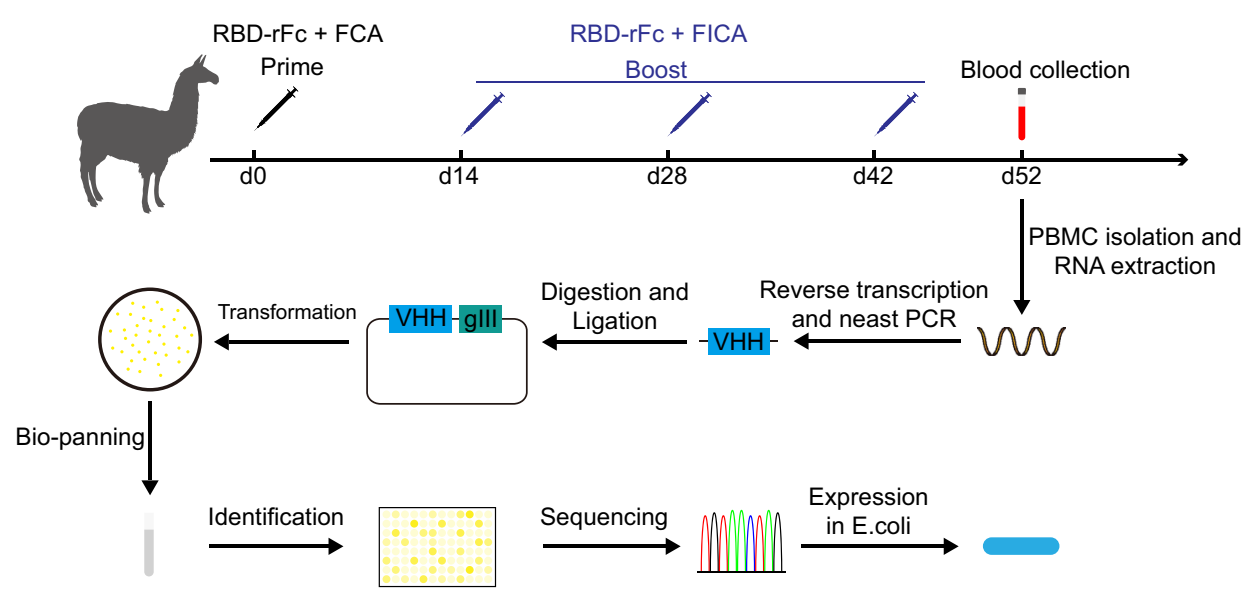

B

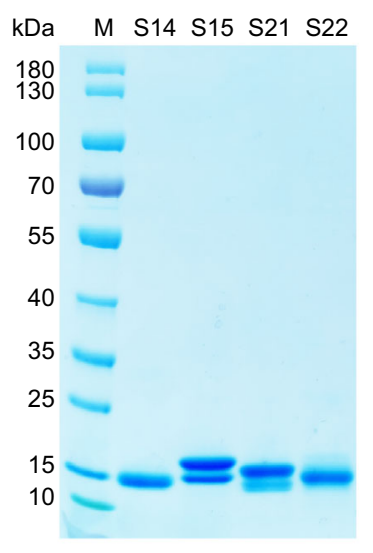

C

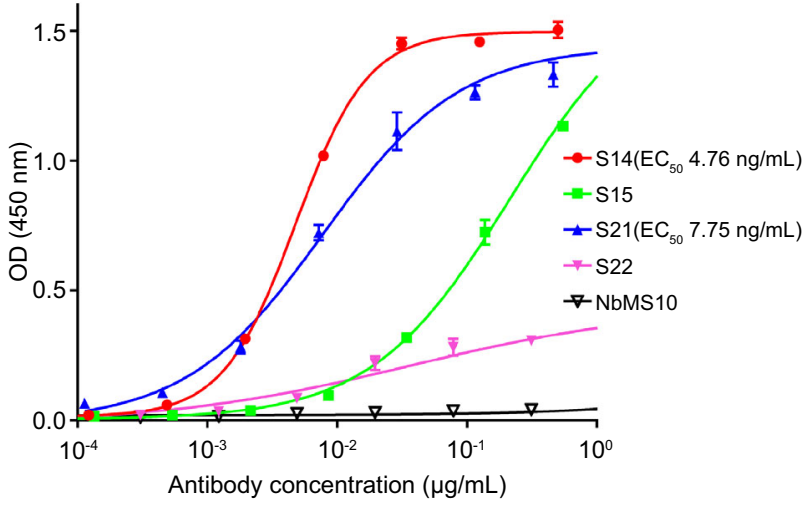

5'-GGTACGTGCTGTTGAACTGTTCC-3') amplified two segments. The smaller band ( $700 \mathrm{bp}$ ) was retrieved to amplify the VHH gene using the second primer pair (forward: $5^{\prime}$-TTTCTATTACTAGGCCCAGCCGGCCGAGTC TGGAGGRRGCTTGGTGCA-3'; reverse: 5'-AAACCGT TGGCCATAATGGCCTGAGGAGACGRTGACSTSGGT C-3') (the $S f i$ restriction site is underlined). The $S$ fiI-digested VHH and phagemid vector pCANTAB5E were ligated using T4 ligase (Thermofisher) and electro-transformed into TG1. SARS-CoV RBD-rFc protein and rabbit IgG-Fc protein were used for bio-panning. After four rounds of panning, monoclonal phages were identified using ELISA. Four positive clones were selected for expression.

\section{Recombinant Protein Expression of SARS-CoV- RBD-Specific Nanobodies and SARS-CoV RBD with Its Mutants}

The $V H H$ genes of the four positive clones were cloned into the protokaryon vector pCold I (Takara) and transformed into E.coli. The recombinant nanobodies with an
$\mathrm{N}$-terminal $6 \times$ His tag were expressed in E.coli induced by isopropyl-beta-D-thiogalactopyranoside (IPTG) and purified using Ni-NTA resin.

The recombinant SARS-CoV RBD and its mutant proteins (Y442A, L472A, N479A, D480A, and T487A) fused with human IgG-Fc tag (SinoBiological) were expressed in 293T cells using the eukaryotic vector pFUSE-IgG1-Fc2 and purified by Protein A resin.

\section{ELISA}

The binding activity between SARS-CoV RBD and nanobodies was detected by ELISA. The ELISA plate was coated with SARS-CoV RBD-rFc protein (or mutant RBDFc proteins for epitope analysis) at $1 \mu \mathrm{g} / \mathrm{mL}$ overnight at $4{ }^{\circ} \mathrm{C}$. After blocking with $3 \%$ BSA for $1 \mathrm{~h}$ at $37^{\circ} \mathrm{C}$, serially diluted nanobodies were added and incubated for $45 \mathrm{~min}$ at $37^{\circ} \mathrm{C}$. Next, horseradish peroxidase (HRP)conjugated mouse anti-His-tag antibody (1:5000) was added and incubated for $30 \mathrm{~min}$ at $37^{\circ} \mathrm{C}$. And then $3,3^{\prime}, 5,5^{\prime}$-tetramethylbenzidine (TMB) substrate was added 
and stopped with $1 \mathrm{~N} \mathrm{H}_{2} \mathrm{SO}_{4}$. The absorbance at $450 \mathrm{~nm}$ was measured using a microplate reader (BioTeck). A MERS-CoV-RBD-specific nanobody NbMS10 (Zhao et al. 2018) was used as a negative control.

Competitive ELISA was performed in a similar manner. Briefly, the plate was coated with SARS-CoV S1 protein (SinoBiological) at $6 \mu \mathrm{g} / \mathrm{mL}$ overnight at $4{ }^{\circ} \mathrm{C}$. After blocking with $3 \% \mathrm{BSA}$ for $1 \mathrm{~h}$ at $37^{\circ} \mathrm{C}$, ACE2 protein fused with human IgG-Fc tag (SinoBiological) at $6 \mu \mathrm{g} / \mathrm{mL}$ and serially diluted nanobodies were simultaneously added and incubated for $45 \mathrm{~min}$ at $37^{\circ} \mathrm{C}$. Then, HRP-conjugated goat anti-Fc-tag antibody (1:4000) was added and incubated for $30 \mathrm{~min}$ at $37{ }^{\circ} \mathrm{C}$. The subsequent procedures were the same as described above.

\section{Pseudovirus Neutralization Assay}

The SARS-CoV pseudovirus neutralization assay was performed as previously described (Zhao et al. 2013). Briefly, 293T cells were co-transfected with a plasmid encoding Env-defective and luciferase-expressing HIV-1 genome (pNL4-3.Luc.R-.E-) and a plasmid expressing SARS-CoV spike protein. After $36 \mathrm{~h}$, the supernatant containing SARS-CoV pseudovirus particles was harvested and stored at $-80{ }^{\circ} \mathrm{C}$. Then, $500 \mathrm{TCID}_{50}$ of SARS-CoV pseudovirus was incubated with serially diluted nanobodies for $1 \mathrm{~h}$ at $37^{\circ} \mathrm{C}$. Huh-7 cells were added and cultured for 48 h. Substrate (PerkinElmer) containing lysis was added and reacted for $2 \mathrm{~min}$. The mixture was transferred into a white plate and the relative light unit (RLU) was read using a luminometer (Promega). The inhibition rate was calculated as follows:

Inhibition rate $(\%)=[(\mathrm{RLU}$ of pseudovirus control $)$

$-($ RLU of samples $)] /[$ (RLU of pseudovirus control)

$-($ RLU of cell control $)] \times 100 \%$.

The $\mathrm{IC}_{50}$ (the $50 \%$ inhibition concentration) was calculated by GraphPad Prism.

\section{Bio-layer Interferometry}

The binding affinity between SARS-CoV RBD-Fc and S14 was measured using a gator (Probe Life). Recombinant SARS-CoV RBD-Fc protein $(100 \mathrm{nmol} / \mathrm{L})$ was captured using anti-Fc probes. The probes were individually inserted into buffer $(0.2 \%$ IgG-free BSA and $0.01 \%$ Tween 20 in PBS) containing $\mathrm{S} 14$ of different concentrations (from $25 \mathrm{nmol} / \mathrm{L}$ to $1.56 \mathrm{nmol} / \mathrm{L}$ ) for association and then inserted into buffer $(0.2 \%$ IgG-free BSA and $0.01 \%$ tween 20 in
PBS) for disassociation. The wave shifts were analyzed using Gator software and fitted to a 1:1 binding model.

\section{Flow Cytometry}

Serially diluted S14 or PBS was incubated with SARS-CoV RBD-rFc (rabbit Fc) protein $(5 \mu \mathrm{g} / \mathrm{mL}$ ) for $30 \mathrm{~min}$ at room temperature. Hela-ACE2 cells were then added and incubated for another $30 \mathrm{~min}$ at $37^{\circ} \mathrm{C}$. Fluorescein isothiocyanate (FITC)-conjugated goat anti-rabbit antibody (1:100) was added and incubated for $30 \mathrm{~min}$ at $37^{\circ} \mathrm{C}$. The cells were analyzed via flow cytometry. NbMS10 was used as the negative control.

\section{Results}

\section{Generation of SARS-CoV-RBD-Specific Nanobodies}

SARS-CoV-RBD-specific nanobodies were generated using standard phage display technology from alpacas immunized with recombinant SARS-CoV RBD-rFc (Fig. 1A). After four rounds of panning and phage clone identification, a total of four positive clones, named S14, S15, S21 and S22, were selected by ELISA. Then, their $V H H$ genes were subcloned into an E. coli expression vector, and nanobodies were purified via Ni-NTA affinity chromatography and verified by SDS-PAGE. The results showed that the molecular weight of the four nanobodies was approximately $16 \mathrm{kDa}$, which was in agreement with their theoretical molecular weights (Fig. 1B). ELISA results further showed that three of the four nanobodies (S14, S15, and S21) bound well and S22 bound weakly to recombinant SARS-CoV RBD-rFc, while the MERS-CoV nanobody NbMS10 showed no binding activity (Fig. 1C).

\section{Characterization of SARS-CoV Nanobody S14}

Based on the ELISA results, S14 was chosen for further characterization. The results of another ELISA showed that S14 fused with human IgG-Fc (S14-Fc) bound well to recombinant SARS-CoV S with an $\mathrm{EC}_{50}$ of $3.76 \mathrm{ng} / \mathrm{mL}$, while the MERS-CoV antibody NbMS10-Fc showed no binding activity (Fig. 2A). Bio-layer interferometry was performed to determine the binding kinetics of S14 to SARS-CoV RBD. The results showed that S14 has a favorable binding activity to SARS-CoV RBD, with an equilibrium dissociation constant $\left(K_{\mathrm{d}}\right)$ of $143 \mathrm{pmol} / \mathrm{L}$ (Fig. 2B). The results of the SARS-CoV pseudovirus neutralization assay showed that S14 could efficiently inhibit the entry of pseudovirus into the target Huh-7 cells, 


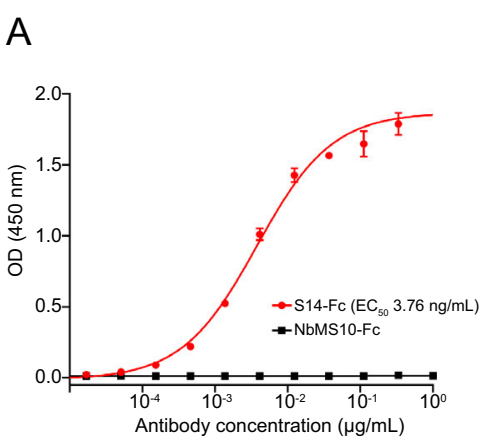

\section{$B$}

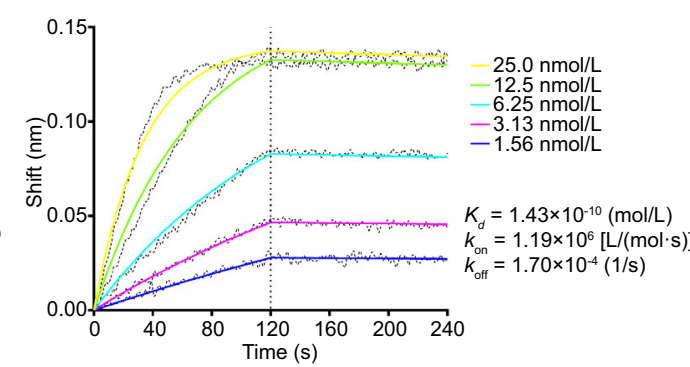

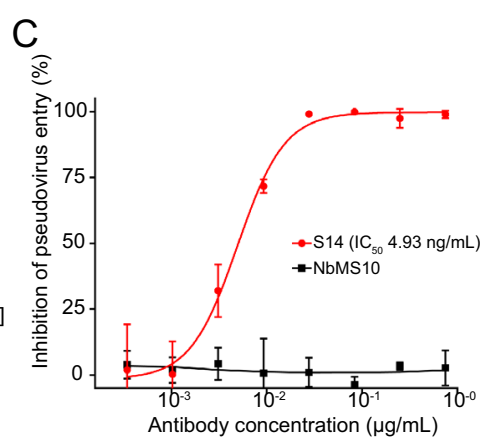

Fig. 2 Characterization of SARS-CoV nanobody S14. A Evaluation of the binding activity between SARS-CoV S and nanobody S14. Results are presented as the mean values of optical density at the absorbance of $450 \mathrm{~nm} \pm$ standard deviation $(\mathrm{n}=2)$. B Bio-layer

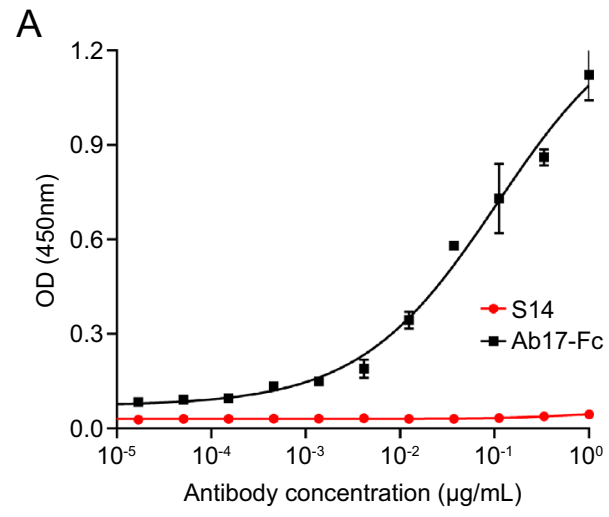

\section{B}

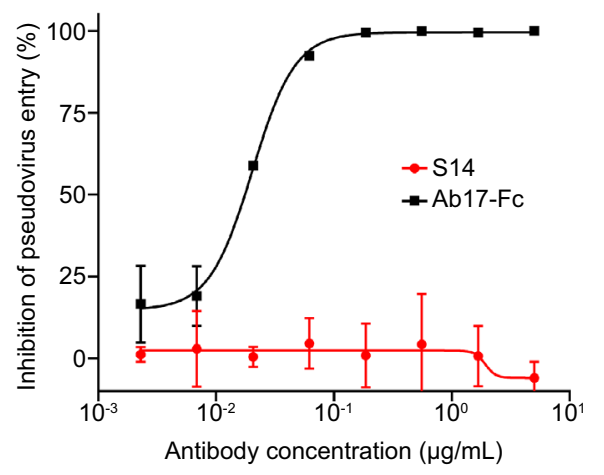

Fig. 3 Evaluation of the cross-reaction of nanobody S14 against SARS-CoV-2. A Evaluation of the binding activity between SARSCoV-2 RBD and nanobody S14. Results are presented as the mean values of optical density at the absorbance of $450 \mathrm{~nm} \pm$ standard deviation $(\mathrm{n}=2)$. B SARS-CoV-2 pseudovirus neutralization. The results are presented as the mean inhibition rates \pm standard deviation $(\mathrm{n}=2)$. Ab17-Fc: A monoclonal antibody against SARS-CoV-2.

with an $\mathrm{IC}_{50}$ of $4.93 \mathrm{ng} / \mathrm{mL}$ (Fig. 2C), while NbMS10 showed no inhibitory activity, as expected. Meanwhile, S14 showed no binding activity against SARS-CoV-2 RBD (Fig. 3A) nor neutralization activity against SARS-CoV-2 pseudovirus (Fig. 3B). These results demonstrate that S14 is a potent SARS-CoV-specific neutralizing nanobody. interferometry. The light-wave shifts were recorded and curves were fitted by gator (Probe life). C SARS-CoV pseudovirus neutralization assay. The results are presented as the mean inhibition rates \pm standard deviation $(\mathrm{n}=2)$.

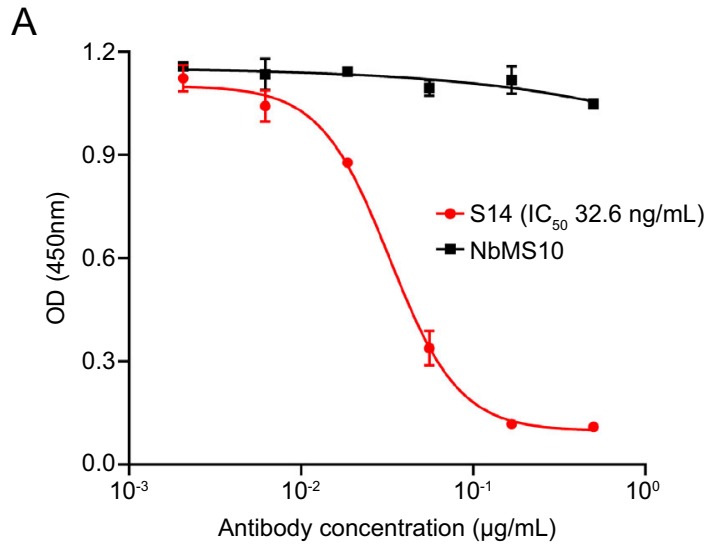

B

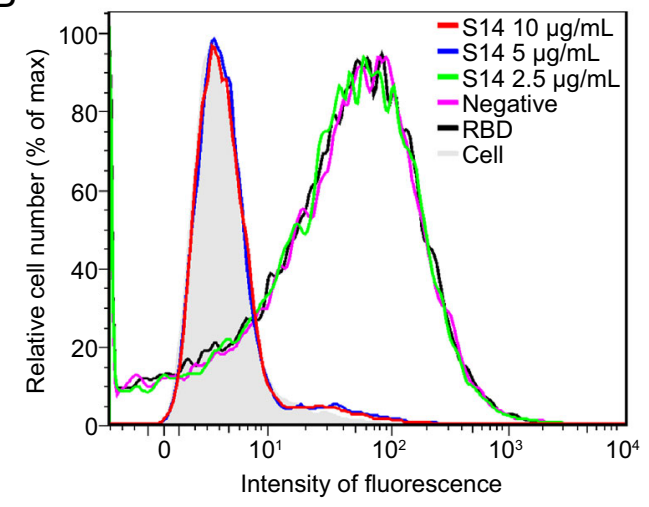

Fig. 4 Neutralization mechanism of SARS-CoV nanobody S14. A Competitive ELISA. Results are presented as the mean values of optical density at the absorbance of $450 \mathrm{~nm} \pm$ standard deviation $(n=2)$. B Flow cytometry analysis of S14 in inhibiting the binding between SARS-CoV RBD and cell-associated ACE2 receptor.

\section{Neutralization Mechanism of SARS-CoV Nanobody S14}

To investigate the mechanism of S14 mediated neutralization, competitive binding assays were performed. As 
shown in Fig. 4A, S14 blocked the binding between soluble ACE2 and SARS-CoV S1 in a dose-dependent manner, while the negative control NbMS10 failed to do so. Meanwhile, the flow cytometry assay also showed that high concentrations of $\mathrm{S} 14$ blocked the binding of SARS-CoV RBD to recombinant ACE2 expressed in Hela-ACE2 cells. However, a low concentration of S14 and NbMS10 did not affect RBD-ACE2 binding (Fig. 4B). These results showed that S14 directly impaired the interaction between SARSCoV RBD and ACE2.

\section{Epitope Analysis}

The structure of SARS-CoV spike RBD complexed with ACE2 has already been well resolved (Li et al. 2005). In the complex interface, residues Y442, L472, N479, D480, and T487 play an important role in host tropism and crossspecies infections of SARS-CoV (Li 2013). To determine whether these mutations were involved in S14-mediated neutralization, we produced a series of RBD mutants, including Y442A, L472A, N479A, D480A, and T487A, and subjected them to ELISA. The results showed that S14 reacted well with all of the above mutants (Fig. 5), suggesting that the neutralization activity of S14 was not affected by these specific mutations.

\section{Discussion}

In this study, using routine phage display technology, we identified a nanobody S14 with high binding affinity to SARS-CoV RBD $\left(K_{\mathrm{d}}=143 \mathrm{pmol} / \mathrm{L}\right)$ as well as inhibition of pseudovirus entry with an $\mathrm{IC}_{50}$ of $4.93 \mathrm{ng} / \mathrm{mL}$, which was expected to be a potent candidate. SARS-CoV RBD is a major determinant (Chen et al. 2005). Several antibodies targeting RBD have shown promising therapeutic value in vitro and in vivo. MAb201 (Greenough et al. 2005),

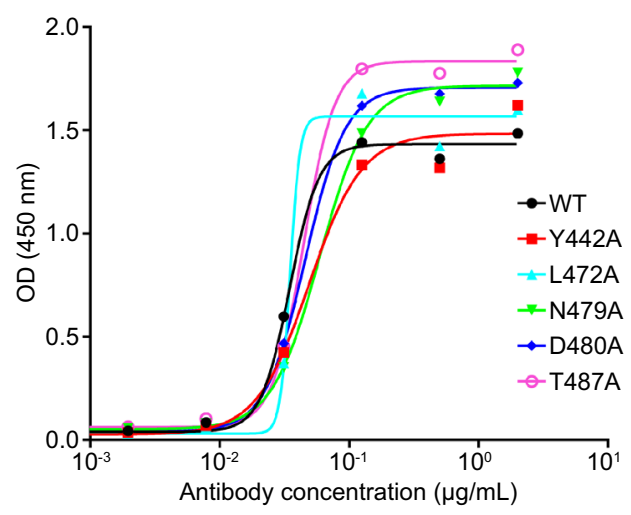

Fig. 5 Epitope analysis of nanobody S14 binding to SARS-CoV RBD. The results are presented as values of optical density at the absorbance of $450 \mathrm{~nm}$. generated from human immunoglobulin transgenic mice, showed an affinity constant $\left(K_{\mathrm{d}}\right)$ of $34 \mathrm{nmol} / \mathrm{L}$ with $\mathrm{S} 590$ (aa 1-590). This could significantly decrease the viral load in mice challenged with SARS-CoV. The human IgG1 form of 80R (Sui et al. 2004), generated from a nonimmune human antibody library, had a comparable binding affinity $\left(K_{\mathrm{d}}=1.59 \mathrm{nmol} / \mathrm{L}\right)$ to $\mathrm{S} 1$ with the receptor ACE2 $\left(K_{\mathrm{d}}=1.70 \mathrm{nmol} / \mathrm{L}\right)$. It reduced more than $4 \mathrm{logs}$ of lung viral load in BALB/c model at $12.5 \mathrm{mg} / \mathrm{kg}$ of body weight (Sui et al. 2005). Another antibody, IgG1 m396 (Prabakaran et al. 2006), with the best binding affinity $\left(K_{\mathrm{d}}=4.6 \mathrm{pmol} / \mathrm{L}\right)$ has been reported to inhibit pseudovirus entry with an $\mathrm{IC}_{50}$ of $10 \mathrm{ng} / \mathrm{mL}$. Considering the high correlation between pseudovirus and authentic coronavirus (Han et al. 2004; Zhao et al. 2013; Hu et al. 2020), similar neutralization potency of $\mathrm{S} 14$ can be expected in infectious SARS-CoV. Further validation in animal models of infectious SARS-CoV would provide more efficacy data.

The development of conventional antibodies requires considerable time and money because they usually require a mammalian expression system for production. In contrast, nanobodies can be easily expressed in microbial systems, such as bacteria, yeasts, and fungi (Mir et al. 2020). Frenken et al. reported that some nanobodies could be secreted by $S$. cerevisiae at levels over $100 \mathrm{mg} / \mathrm{L}$ in shake flask cultures (Frenken et al. 2000). In addition, nanobodies are thermostable. For example, nanobodies maintained full binding capacities after one week at $37{ }^{\circ} \mathrm{C}$ (Arbabi Ghahroudi et al. 1997). This may greatly facilitate storage and transportation for clinical applications without the requirement of strict cryopreservation. The first approved caplacizumab (Scully et al. 2019), a therapeutic nanobody for acquired thrombotic thrombocytopenic purpura (aTTP), suggests an extensive application prospect for nanobodies. The promising neutralization profile of S14 described here warrants further development as a therapeutic nanobody against SARS-CoV.

In summary, we identified and characterized a specific nanobody against SARS-CoV with high affinity. The in vitro data showed that $\mathrm{S} 14$ can be further tested in live virus and animal studies with some refinement of S14 to determine whether it can be used as prophylaxis or treatment of SARS, given that our experiment is no longer affected by COVID-19. In addition, similar strategies may be applied to other viruses, such as SARS-CoV-2.

Acknowledgements This article is in memory of Prof. Yusen Zhou for his contributions to the project conception. We also thank Shihui Sun for her excellent technical support. This study was supported by SKLPBS1805 and 2019-JCJQ-JJ-167 (to G.Z.). C.F.Q. was supported by the National Science Fund for Distinguished Young Scholar (No. 81925025), and the Innovative Research Group (No. 81621005) from the NSFC, and the Innovation Fund for Medical Sciences (No. 2019-I2M-5-049) from the Chinese Academy of Medical Sciences. 
Author Contributions CFQ and GYZ design the experiments. JFL carried out the experiments with the help of LH, SHQ, YHC, XLZ and SXH. JFL and YQD analyzed the data and wrote the paper. CFQ checked and finalized the manuscript. All authors read and approved the final manuscript.

\section{Compliance with Ethical Standards}

Conflict of Interest CFQ and JFL have filed a patent related to antiSARS-CoV nanobody.

Animal and Human Rights Statement The research protocol was approved by the Animal Experimentation Ethics Committee of Shanxi Agricultural University (2018). All institutional and national guidelines for the care and use of laboratory animals were followed.

Open Access This article is licensed under a Creative Commons Attribution 4.0 International License, which permits use, sharing, adaptation, distribution and reproduction in any medium or format, as long as you give appropriate credit to the original author(s) and the source, provide a link to the Creative Commons licence, and indicate if changes were made. The images or other third party material in this article are included in the article's Creative Commons licence, unless indicated otherwise in a credit line to the material. If material is not included in the article's Creative Commons licence and your intended use is not permitted by statutory regulation or exceeds the permitted use, you will need to obtain permission directly from the copyright holder. To view a copy of this licence, visit http://creativecommons. org/licenses/by/4.0/.

\section{References}

Anderson LJ, Tong S (2010) Update on SARS research and other possibly zoonotic coronaviruses. Int $\mathrm{J}$ Antimicrob Agents 36(Suppl 1):S21-25

Arbabi Ghahroudi M, Desmyter A, Wyns L, Hamers R, Muyldermans S (1997) Selection and identification of single domain antibody fragments from camel heavy-chain antibodies. FEBS Lett 414:521-526

Chen Z, Zhang L, Qin C, Ba L, Yi CE, Zhang F, Wei Q, He T, Yu W, Yu J, Gao H, Tu X, Gettie A, Farzan M, Yuen KY, Ho DD (2005) Recombinant modified vaccinia virus Ankara expressing the spike glycoprotein of severe acute respiratory syndrome coronavirus induces protective neutralizing antibodies primarily targeting the receptor binding region. J Virol 79:2678-2688

Cheng Y, Wong R, Soo YO, Wong WS, Lee CK, Ng MH, Chan P, Wong KC, Leung CB, Cheng G (2005) Use of convalescent plasma therapy in SARS patients in Hong Kong. Eur J Clin Microbiol Infect Dis 24:44-46

Du L, He Y, Zhou Y, Liu S, Zheng BJ, Jiang S (2009) The spike protein of SARS-CoV-a target for vaccine and therapeutic development. Nat Rev Microbiol 7:226-236

Ebrahimizadeh W, Mousavi Gargari S, Rajabibazl M, Safaee Ardekani L, Zare H, Bakherad H (2013) Isolation and characterization of protective anti-LPS nanobody against V. cholerae O1 recognizing Inaba and Ogawa serotypes. Appl Microbiol Biotechnol 97:4457-4466

Frenken LGJ, van der Linden RHJ, Hermans PWJJ, Bos JW, Ruuls RC, de Geus B, Verrips CT (2000) Isolation of antigen specific Llama VHH antibody fragments and their high level secretion by Saccharomyces cerevisiae. J Biotechnol 78:11-21

Gallagher TM, Buchmeier MJ (2001) Coronavirus spike proteins in viral entry and pathogenesis. Virology 279:371-374
Greenough TC, Babcock GJ, Roberts A, Hernandez HJ, Thomas WD Jr, Coccia JA, Graziano RF, Srinivasan M, Lowy I, Finberg RW, Subbarao K, Vogel L, Somasundaran M, Luzuriaga K, Sullivan JL, Ambrosino DM (2005) Development and characterization of a severe acute respiratory syndrome-associated coronavirusneutralizing human monoclonal antibody that provides effective immunoprophylaxis in mice. J Infect Dis 191:507-514

Hamers-Casterman C, Atarhouch T, Muyldermans S, Robinson G, Hamers C, Songa EB, Bendahman N, Hamers R (1993) Naturally occurring antibodies devoid of light chains. Nature 363:446-448

Han DP, Kim HG, Kim YB, Poon LL, Cho MW (2004) Development of a safe neutralization assay for SARS-CoV and characterization of S-glycoprotein. Virology 326:140-149

He Y, Zhou Y, Liu S, Kou Z, Li W, Farzan M, Jiang S (2004) Receptor-binding domain of SARS-CoV spike protein induces highly potent neutralizing antibodies: implication for developing subunit vaccine. Biochem Biophys Res Commun 324:773-781

Hu J, Gao Q, He C, Huang A, Tang N, Wang K (2020) Development of cell-based pseudovirus entry assay to identify potential viral entry inhibitors and neutralizing antibodies against SARS-CoV2. Genes Dis 7:551-557

Ksiazek TG, Erdman D, Goldsmith CS, Zaki SR, Peret T, Emery S, Tong S, Urbani C, Comer JA, Lim W, Rollin PE, Dowell SF, Ling AE, Humphrey CD, Shieh WJ, Guarner J, Paddock CD, Rota P, Fields B, DeRisi J, Yang JY, Cox N, Hughes JM, LeDuc JW, Bellini WJ, Anderson LJ, Group SW (2003) A novel coronavirus associated with severe acute respiratory syndrome. N Engl J Med 348:1953-1966

Kuiken T, Fouchier RAM, Schutten M, Rimmelzwaan GF, van Amerongen G, van Riel D, Laman JD, de Jong T, van Doornum G, Lim W, Ling AE, Chan PKS, Tam JS, Zambon MC, Gopal R, Drosten C, van der Werf S, Escriou N, Manuguerra J-C, Stöhr K, Peiris JSM, Osterhaus ADME (2003) Newly discovered coronavirus as the primary cause of severe acute respiratory syndrome. Lancet 362:263-270

Lauwereys M, Arbabi Ghahroudi M, Desmyter A, Kinne J, Holzer W, De Genst E, Wyns L, Muyldermans S (1998) Potent enzyme inhibitors derived from dromedary heavy-chain antibodies. EMBO J 17:3512-3520

Li F (2013) Receptor recognition and cross-species infections of SARS coronavirus. Antiviral Res 100:246-254

Li F, Li W, Farzan M, Harrison SC (2005) Structure of SARS coronavirus spike receptor-binding domain complexed with receptor. Science 309:1864-1868

Liang G, Chen Q, Xu J, Liu Y, Lim W, Peiris JS, Anderson LJ, Ruan L, Li H, Kan B, Di B, Cheng P, Chan KH, Erdman DD, Gu S, Yan X, Liang W, Zhou D, Haynes L, Duan S, Zhang X, Zheng H, Gao Y, Tong S, Li D, Fang L, Qin P, Xu W, Group SDW (2004) Laboratory diagnosis of four recent sporadic cases of community-acquired SARS, Guangdong Province, China. Emerg Infect Dis 10:1774-1781

Lu R, Zhao X, Li J, Niu P, Yang B, Wu H, Wang W, Song H, Huang B, Zhu N, Bi Y, Ma X, Zhan F, Wang L, Hu T, Zhou H, Hu Z, Zhou W, Zhao L, Chen J, Meng Y, Wang J, Lin Y, Yuan J, Xie Z, Ma J, Liu WJ, Wang D, Xu W, Holmes EC, Gao GF, Wu G, Chen W, Shi W, Tan W (2020) Genomic characterisation and epidemiology of 2019 novel coronavirus: implications for virus origins and receptor binding. Lancet 395:565-574

Mir MA, Mehraj U, Sheikh BA, Hamdani SS (2020) Nanobodies: the "magic bullets" in therapeutics, drug delivery and diagnostics. Hum Antibodies 28:29-51

Pearson H, Clarke T, Abbott A, Knight J, Cyranoski D (2003) SARS: what have we learned? Nature 424:121-126

Peiris JS, Yuen KY, Osterhaus AD, Stohr K (2003) The severe acute respiratory syndrome. N Engl J Med 349:2431-2441 
Prabakaran P, Gan J, Feng Y, Zhu Z, Choudhry V, Xiao X, Ji X, Dimitrov DS (2006) Structure of severe acute respiratory syndrome coronavirus receptor-binding domain complexed with neutralizing antibody. J Biol Chem 281:15829-15836

Roberts A, Thomas WD, Guarner J, Lamirande EW, Babcock GJ, Greenough TC, Vogel L, Hayes N, Sullivan JL, Zaki S, Subbarao K, Ambrosino DM (2006) Therapy with a severe acute respiratory syndrome-associated coronavirus-neutralizing human monoclonal antibody reduces disease severity and viral burden in golden Syrian hamsters. J Infect Dis 193:685-692

Scully M, Cataland SR, Peyvandi F, Coppo P, Knobl P, Kremer Hovinga JA, Metjian A, de la Rubia J, Pavenski K, Callewaert F, Biswas D, De Winter H, Zeldin RK, Investigators H (2019) Caplacizumab treatment for acquired thrombotic thrombocytopenic Purpura. N Engl J Med 380:335-346

Subbarao K, McAuliffe J, Vogel L, Fahle G, Fischer S, Tatti K, Packard M, Shieh WJ, Zaki S, Murphy B (2004) Prior infection and passive transfer of neutralizing antibody prevent replication of severe acute respiratory syndrome coronavirus in the respiratory tract of mice. J Virol 78:3572-3577

Sui J, Li W, Murakami A, Tamin A, Matthews LJ, Wong SK, Moore MJ, Tallarico AS, Olurinde M, Choe H, Anderson LJ, Bellini WJ, Farzan M, Marasco WA (2004) Potent neutralization of severe acute respiratory syndrome (SARS) coronavirus by a human $\mathrm{mAb}$ to $\mathrm{S} 1$ protein that blocks receptor association. Proc Natl Acad Sci USA 101:2536-2541

Sui J, Li W, Roberts A, Matthews LJ, Murakami A, Vogel L, Wong SK, Subbarao K, Farzan M, Marasco WA (2005) Evaluation of human monoclonal antibody $80 \mathrm{R}$ for immunoprophylaxis of severe acute respiratory syndrome by an animal study, epitope mapping, and analysis of spike variants. J Virol 79:5900-5906
Traggiai E, Becker S, Subbarao K, Kolesnikova L, Uematsu Y, Gismondo MR, Murphy BR, Rappuoli R, Lanzavecchia A (2004) An efficient method to make human monoclonal antibodies from memory B cells: potent neutralization of SARS coronavirus. Nat Med 10:871-875

Tsunetsugu-Yokota Y, Ohnishi K, Takemori T (2006) Severe acute respiratory syndrome (SARS) coronavirus: application of monoclonal antibodies and development of an effective vaccine. Rev Med Virol 16:117-131

Wang W, Hou X, Yang X, Liu A, Tang Z, Mo F, Yin S, Lu X (2019) Highly sensitive detection of CTLA-4-positive T-cell subgroups based on nanobody and fluorescent carbon quantum dots. Oncol Lett 18:109-116

Zaki AM, van Boheemen S, Bestebroer TM, Osterhaus AD, Fouchier RA (2012) Isolation of a novel coronavirus from a man with pneumonia in Saudi Arabia. N Engl J Med 367:1814-1820

Zhao G, Du L, Ma C, Li Y, Li L, Poon VK, Wang L, Yu F, Zheng BJ, Jiang S, Zhou Y (2013) A safe and convenient pseudovirusbased inhibition assay to detect neutralizing antibodies and screen for viral entry inhibitors against the novel human coronavirus MERS-CoV. Virol J 10:266

Zhao G, He L, Sun S, Qiu H, Tai W, Chen J, Li J, Chen Y, Guo Y, Wang Y, Shang J, Ji K, Fan R, Du E, Jiang S, Li F, Du L, Zhou Y (2018) A novel nanobody targeting middle east respiratory syndrome coronavirus (MERS-CoV) receptor-binding domain has potent cross-neutralizing activity and protective efficacy against MERS-CoV. J Virol 92:e00837-e918 